\title{
Um programa de triagem populacional para toxoplasmose?
}

\author{
Eliana Amaral
}

Figueiró-Filho et al. ${ }^{1}$ apresentam, neste fascículo, interessantes resultados de um programa de triagem populacional para toxoplasmose em gestantes, no Estado do Mato Grosso do Sul, por um ano, a partir de sangue colhido em papel de filtro. Embora seja uma importante contribuição no debate da inclusão da triagem sorológica na rotina pré-natal como estratégia de prevenção da toxoplasmose congênita (não recomendada pelo Ministério da Saúde²), alguns pontos merecem discussão.

Os resultados desta triagem são diferentes de outros estudos populacionais brasileiros. Em um trabalho recente foi observada taxa de prevalência de 56,1\% (IC 95\% $=54-58,2$ ) em amostras de todas as gestantes do SUS do município de Campinas ${ }^{3}$ e outro estudo mostrou $70,7 \%$ de prevalência em maternidades do SUS de Cuiabá ${ }^{4}$. No trabalho agora publicado os autores observaram que $91,6 \%$ das gestantes sul-mato-grossenses tinham infecção prévia à gestação e que $8 \%$ das gestantes eram suscetíveis para toxoplasmose. Além disto, apenas 0,42\% das amostras (136 casos) apresentavam IgM reagente, cifra muito inferior aos 2,5\% (IC 95\% = 1,3-2,4) observados na população de gestantes do SUS de Campinas ${ }^{3}$. Estes dados sugerem um menor risco de infecção congênita conseqüente naquele estado, comparado com as outras regiões citadas.

O programa conseguiu uma excelente cobertura da triagem sorológica $(95,3 \%)$, realizando confirmação da infecção recente por teste de avidez de IgG na primeira amostra sanguínea em 92\% dos casos com IgM reagente, o que é considerado ideal. Entretanto, a idade gestacional média foi de 15,6 semanas na avaliação da avidez, o que está no limite da sua utilidade para datar a infecção materna. Esta é uma dificuldade que qualquer proposta de programa de prevenção por triagem prénatal deve enfrentar - a precocidade da avaliação sorológica completa (até 12 ou 16 semanas, dependendo da técnica utilizada).

Supondo que as 45 grávidas submetidas à amniocentese para PCR eram aquelas que apresentavam avidez baixa (até 30\%) ou intermediária (30-60\%), a pesquisa de infecção fetal teve cobertura de $92 \%$ para os casos onde estaria indicada, outro excelente indicador. A presença do parasita foi detectada em apenas dois (4,5\%) dos pesquisados (ou 0,6/10.000 gestantes triadas). Entre os $81 \%$ dos 137 recém-nascidos das gestantes com IgM positiva acompanhados, obteve-se uma taxa similar de infecção, 3,9\% (4 casos). Usando esta taxa, obtém-se valor similar de infecção congênita (1,2/10.000 gestantes triadas). Esta taxa de infecção congênita é concordante com estudos em populações de países com baixa soroprevalência ${ }^{5}$. É menor que os valores encontrados em estudos de base populacional com triagem neonatal em papel de filtro realizados por Carvalheiro et al. ${ }^{6}(3,3$ / 10.000) em Ribeirão Preto. Correspondem a menos de um décimo dos valores publicados por Spalding et al. ${ }^{7}(28,2 / 10.000)$, que realizaram triagem sorológica pré-natal no alto Uruguai no Rio Grande do Sul, onde a prevalência e incidência de infecção toxoplásmica são muito elevadas.

Figueiró-Filho et al. ${ }^{1}$ não informam, nem discutem, o desempenho da técnica de teste empregada com amostras colhidas em papel de filtro, em pequenas alíquotas. Sabe-se que na triagem neonatal usando amostra de papel de filtro, a taxa de falso-negativo está em torno de 20$30 \%{ }^{8}$. As estratégias de triagem e confirmação diagnóstica que aumentem as taxas de falsonegativo são inadequadas, pois podem excluir do acompanhamento, diagnóstico e tratamento precoces as crianças que teriam manifestações mais tardias da infecção congênita, com alterações oftalmológicas, por exemplo, sabidamente importantes como causa de morbidade tardia na toxoplasmose congênita.

Será que, ao utilizar amostra materna em papel de filtro, teria havido mais falso-negativo da IgM, explicando a baixa taxa encontrada? Se isso for verdade, houve uma seleção insuficiente dos casos de risco que necessitariam acompanhamento. Muitos casos com infecção congênita menos 
severa deixaram de ser identificados e tratados precocemente, para reduzir a morbidade da infecção ${ }^{9}$.

Assim, para contribuir com o debate sobre o programa mais adequado de prevenção da toxoplasmose congênita (e por que não da toxoplasmose ocular, sabidamente dependente da transmissão vertical?), discutindo sua operacionalização e chegando a um consenso nacional, será necessário rever os resultados do desempenho dos testes comparando amostra de sangue materno colhido em tubo e papel de filtro. O mesmo se aplica à interpretação da avidez. Será que na amostra em papel de filtro o teste tem o mesmo desempenho?

Os autores não discutem o suporte financeiro, recursos humanos e materiais necessários para implementar o programa, que inclui a triagem de inúmeras outras condições clínicas. Também não se discutem as conseqüências como custo e disponibilidade de espiramicina para uso prénatal, a disponibilidade de PCR nos serviços de referência e outros importantes aspectos quando se propõe a implementação de um programa de triagem. Este é um desafio que temos enfrentado diariamente na região de Campinas, onde os municípios implantaram a triagem sorológica. Entretanto, não há respaldo nos laboratórios de origem para realização da avidez de IgG, que descartaria a amniocentese para PCR e uso de espiramicina em 60\% dos casos de IgM reagente, pois seriam infecções pregressas, segundo dados dos mesmos autores.

Estes questionamentos são apenas alguns dos muitos que deverão ser respondidos antes de se estabelecerem condutas coletivas com o objetivo de orientar os colegas que se dedicam à assistência pré-natal. Sabemos a eficácia das medidas preventivas primárias, higiênico-dietéticas, na redução da doença congênita - não comer carne crua ou mal-cozida, usar luvas no contato com terra, lavar bem os alimentos crus ${ }^{5}$. Entretanto, não temos sido eficientes nem sequer para propagar estas orientações para profissionais médicos, não médicos e para a população, principalmente as gestantes.

Os profissionais e mesmo a literatura estão cheios de dúvidas sobre a importância da toxoplasmose como problema de saúde pública, baseados nos estudos de países desenvolvidos onde é esperada uma menor incidência. Entretanto, o Brasil é o país campeão de toxoplasmose ocular! Também se questiona a eficácia da estratégia de triagem e tratamento antenatal, demonstrada em estudos do tipo antes-depois, mas não avaliada em estudos clínicos randomizados. Não por acaso, os países têm diferentes propostas para os programas de prevenção da doença congênita, variando da prevenção primária exclusiva, (acima citada) até a associação desta com prevenção secundária (nas gestações de risco, com sorologia pré-natal) ou terciária (no recém-nascido afetado, com sorologia neonatal).

A discussão sobre o desempenho dos testes em papel de filtro e as diferenças na taxa de infecção congênita são importantes questões levantadas pelo estudo de Figueiró-Filho et al. ${ }^{1}$. Os pesquisadores brasileiros já acumularam experiências que devem ser compartilhadas e somadas para a busca de um consenso com os gerentes em saúde. Os colegas ginecologistas brasileiros ficarão satisfeitos se pudermos buscar uma posição mais clara sobre um programa de prevenção. Fica meu apelo para que continue o debate científico e que este aproxime aqueles que se interessam pela causa da "morbidade por toxoplasmose".

\section{Referências}

1. Figueiró-Filho EA, Lopes AHA, Senefonte FRA, Souza Júnior VG, Botelho CA, Figueiredo MS, et al. Toxoplasmose aguda: estudo da freqüência, taxa de transmissão vertical e relação entre os testes diagnósticos materno-fetais em gestantes em estado da região Centro-Oeste do Brasil. Rev Bras Ginecol Obstet. 2005;27(5): 442-9.

2. Ministério da Saúde. Programa de humanização do pré-natal e nascimento. Brasília (DF); 2001

3. Stela JH. Rastreamento pré-natal para toxoplasmose na rede básica de saúde em Campinas - prevalência dos diferentes perfis sorológicos e comparação da rotina vigente com uma nova proposta [dissertação]. Campinas: Universidade de Estadual de Campinas; 2004.

4. Leão PRD, Meirelles-Filho, J, Medeiros, SF. Toxoplasmose: soroprevalência em puérperas atendidas pelo 
Sistema Único de Saúde. Rev Bras Ginecol Obstet. 2004;26(8):627-32.

5. Breugelmans M, Naessens A, Foulon W. Prevention of toxoplasmosis during pregnancy: an epidemiologic survey over 22 consecutive years. J Perinat Med. 2004;32(3):211-4.

6. Carvalheiro CG, Mussi-Pinhata MM, Yamamoto AY, De Souza CB, Maciel LM. Incidence of congenital toxoplasmosis estimated by neonatal screening: relevance of diagnostic confirmation in asymptomatic newborn infants. Epidemiol Infect. 2005; 133(3):485-91.

7. Spalding SM, Amendoeira MRR, Ribeiro LC, Silveira C, Garcia AP, Camillo-Coura L. Estudo prospectivo de gestantes e seus bebês com risco de transmissão de toxoplasmose congênita em município do Rio Grande do Sul. Rev Soc Bras Med Trop. 2003;36(4):483-91.

8. Naessens A, Jenum PA, Pollak A, Decoster A, Lappalainen M, Villena I, et al. Diagnosis of congenital toxoplasmosis in the neonatal period: a multicenter evaluation. J Pediatr. 1999;135(6):714-9.

9. Wallon M, Kodjikian L, Binquet C, Garweg J, Fleury J, Quantin C, et al. Long-term ocular prognosis in 327 children with congenital toxoplasmosis. Pediatrics. 2004;113(6):1567-72. 